\title{
A costing analysis of B-GAP: index-linked HIV testing for children and adolescents in Zimbabwe
}

\author{
Arthi Vasantharoopan 1* ${ }^{*}$, Hendramoorthy Maheswaran², Victoria Simms ${ }^{3,4}$, Chido Dziva Chikwari, \\ Tariro Chigwenah ${ }^{6}$, Rudo Chikodzore ${ }^{7}$, Khulamuzi Nyathi ${ }^{8}$, Gertrude Ncube ${ }^{9}$, Rashida A. Ferrand ${ }^{4,5}$ and \\ Lorna Guinness ${ }^{10}$
}

\begin{abstract}
Background: By testing children and adolescents of HIV positive caretakers, index-linked HIV testing, a targeted HIV testing strategy, has the ability to identify high risk children and adolescents earlier and more efficiently, compared to blanket testing. We evaluated the incremental cost of integrating index-linked HIV testing via three modalities into HIV services in Zimbabwe.

Methods: A mixture of bottom-up and top-down costing was employed to estimate the provider cost per test and per HIV diagnosis for 2-18 year olds, through standard of care testing, and the incremental cost of index-linked HIV testing via three modalities: facility-based testing, home-based testing by a healthcare worker, and testing at home by the caregiver using an oral mucosal transudate test. In addition to interviews, direct observation and study process data, facility registries were abstracted to extract outcome data and resource use. Costs were converted to 2019 constant US\$.

Results: The average cost per standard of care test in urban facilities was US\$5.91 and US\$7.15 at the rural facility. Incremental cost of an index-linked HIV test was driven by the uptake and number of participants tested. The lowest cost approach in the urban setting was home-based testing (US\$6.69) and facility-based testing at the rural clinic (US\$5.36). Testing by caregivers was almost always the most expensive option (rural US\$62.49, urban US\$17.49).
\end{abstract}

Conclusions: This is the first costing analysis of index-linked HIV testing strategies. Unit costs varied across sites and with uptake. When scaling up, alternative testing solutions that increase efficiency such as index-linked HIV testing of the entire household, as opposed to solely targeting children/adolescents, need to be explored.

Keywords: HIV, Index-linked HIV testing, Community-based HIV testing, Home-based HIV testing, HIV assistedtesting, Costing analysis

\footnotetext{
* Correspondence: arthi.vasantharoopan@|shtm.ac.uk

'Department of Infectious Disease Epidemiology, London School of Hygiene and Tropical Medicine, London, UK

Full list of author information is available at the end of the article
}

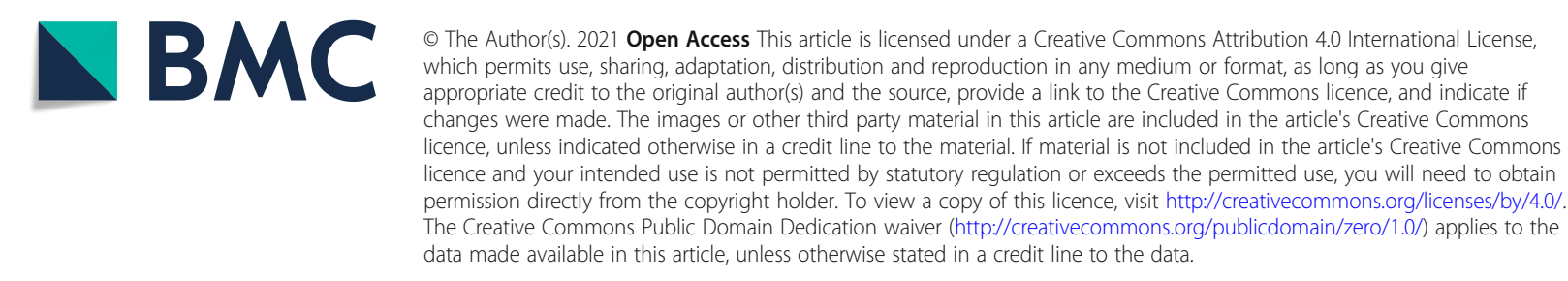




\section{Background}

Since 2010, 1.4 million new HIV infections in children have been averted worldwide, while HIV mortality among children has halved [1,2]. Despite this progress, 150,000 children were newly infected in 2019, falling short of the 2018 target to reduce new HIV infections in children to 40,000 [3]. In addition, HIV treatment coverage among children is significantly lower than among adults, likely due to higher levels of under-diagnosis [4]. Furthermore, many children present to clinical services and start antiretroviral therapy (ART) in older childhood and adolescence when they have developed advanced disease, with consequent poorer outcomes [5]. Notably, adolescents are the only age-group in whom HIV-related mortality has not declined [5-8]. HIV testing and counselling approaches aimed at the timely diagnosis and linkage to care of children and adolescents in high HIV prevalence settings are therefore urgently needed.

Index-linked testing refers to screening family, household or other contacts of a case for a disease. Indexlinked HIV testing has been widely used to identify higher risk individuals, and thus a high-yielding strategy for HIV testing [9]. In sub-Saharan Africa children and adolescents living in households with known HIVpositive adults are more likely to be HIV-positive, and are often untested and untreated [9-11]. Index-linked HIV testing (ILHIVT), whereby children living with adults with HIV are targeted for testing, has the potential to identify high-risk, difficult to access children and adolescents, and to improve yield $[9,12,13]$.

While WHO guidelines recommend offering testing to children of HIV-positive adults, countries in Eastern and Southern Africa have yet to integrate this policy into routine service delivery $[9,12,14]$. The paucity of data on effectiveness, cost and cost-effectiveness of ILHIVT may be one factor preventing its scale up. As there are no costing studies of ILHIVT within sub-Saharan Africa, the cost implications and cost-effectiveness of including this strategy within HIV service delivery programs is unknown.

The Bridging the Gap in HIV testing and care for Children in Zimbabwe (B-GAP) study assessed the effectiveness and cost of a multi-option ILHIVT strategy in both urban and rural settings in Zimbabwe [14]. This paper is the cost analysis of B-GAP estimating the cost of providing standard of care (SoC) HIV testing -voluntary, facility based HIV testing and counselling (HTC) comparing to the incremental cost of different ILHIVT strategies.

\section{Methods}

\section{B-GAP HIV testing intervention}

In the B-GAP study, individuals with HIV enrolled in and attending care at study clinics, i.e. indexes, were offered HIV testing for any children and adolescents (aged 2-18 years) of unknown HIV status in their household by study staff. Indexes could choose one of three testing options for the child (ren)/adolescent(s): Clinicbased diagnostic testing using a rapid test; home-based rapid diagnostic testing by a healthcare provider; or home-based, caregiver-provider testing using an oral mucosal transudate (OMT) test. All participants diagnosed with HIV were linked to care at their nearest healthcare facility.

\section{Study setting}

ILHIVT was provided at 9 of the 36 primary health care facilities in Bulawayo and Mangwe district in Matebeleland South province in Zimbabwe, (6 urban, 3 rural) selected based on size and accessibility [14]. Adult HIV prevalence in both these provinces is approximately $20 \%$ [14]. The facilities do not routinely employ ILHIVT. Cost data collection took place at 2 urban facilities in Bulawayo, and 1 rural facility located in the Mangwe, sampled by convenience (Table 1).

\section{Costing methods}

We estimated the provider cost of facility level HIV testing and the provision of index-linked testing, following the Global Health Cost Consortium costing guidelines [15]. A combination of bottom-up and top-down costing was employed. First, we estimated the full cost of testing and diagnosis of children and adolescents through SoC facility testing for a 4-month time period before the BGAP intervention (May- August 2018). We then estimated the incremental cost of ILHIVT and diagnosis of participants (September- December 2018) at the same 3 clinics, provided by the three modalities: clinic, healthcare worker testing in the household, and caregivertesting in the household. Costs estimated included personnel, consumables, overheads, building, equipment, training, start-up and transaction costs, but excluded any research related costs.

To gauge personnel time, we undertook a combination of direct observation and face-to-face interviews with clinic and B-GAP staff to quantify resources utilized to deliver all HIV testing models. We used prospective time-tracking diaries and direct observation to measure human resource time spent on different activities. Appendix 1 provides a summarized breakdown of time spent on ILHIVT activities. Prices of test kits were taken from the National Pharmaceutical Corporation of Zimbabwe (NatPharm), as specified by the centralized Matebeleland South pharmacy system. Overheads and other shared clinic costs were allocated to the testing activities based on area of the clinic utilized by each department and patient load depending on the line item. 
Table 1 Characteristics of costing study facilities, as of Sept 2018

\begin{tabular}{|c|c|c|c|}
\hline & Clinic A & Clinic B & Clinic C \\
\hline District & Bulawayo & Bulawayo & Mangwe \\
\hline Setting & Urban & Urban & Rural \\
\hline Catchment Area Population Total & 42,497 & 31,492 & 9137 \\
\hline Catchment Area Population Under 15 yrs & 14,433 & 10,696 & 4066 \\
\hline Catchment Area Population 15 years + & 28,063 & 20,796 & 5071 \\
\hline Overall Facility Visits in 1 Year $^{\mathrm{a}}$ & 50,778 & 77,558 & 5118 \\
\hline HIV Tests Conducted in 1 Year $^{\mathrm{a}}$ & 2541 & 3276 & 1860 \\
\hline Number of people on ART as of Sept 2018 & 4478 & $4625^{b}$ & 960 \\
\hline
\end{tabular}

${ }^{a}$ Based on one year of facility registries: Oct 2017 - Sept 2018

${ }^{b}$ Due to missing records, this tally is current as of June 2017

All resources used were converted into costs using financial data collected from B-GAP project accounts, Bulawayo City Council and the district and provincial medical offices in Matebeleland South. Salaries of study staff who conducted ILHIVT, were substituted with those of facility primary care counsellors who would carry out this work in routine clinical settings. Equipment, building, training and start-up costs were annualized using expected length of life determined by WHO cost effectiveness and strategic planning prices for tradable goods, and discounted at a rate of 3\% [16]. Due to the instability of the Zimbabwean currency, we estimated costs in US dollars. We converted all real-time gross settlement (RTGS) dollars, the Zimbabwean currency, into USD using the exchange rate at the time when the financial data was provided, using the Reserve Bank of Zimbabwe exchange rates [17]. All costs were converted to 2019 constant USD using the GDP deflator for the United States [18]. A detailed description of the cost data collection methods is provided in Appendix 2 and 3.

\section{Healthcare outputs}

We used clinic registers to determine the outputs of the standard facility-based HIV testing service including numbers of: tests administered; HIV positive test results; tests administered to $2-18$ year olds; positive test results among 2-18 year olds. We used B-GAP study data to determine the outputs of the three ILHIVT modalities, including the number of: index cases screened; children and adolescents identified through index cases; children and adolescents tested by the three modalities; HIVpositive children and adolescents diagnosed.

\section{Data analysis}

Unit cost per SoC HIV test in clinics, and per diagnosis at each clinic were calculated by dividing the total 4 month costs of testing at each clinic by the total number of people tested, and the number identified as positive, respectively. As no additional resources were consumed at clinics to test children/adolescents we assumed the cost per test to be the same as for adults.

The incremental cost of ILHIVT was calculated by assessing the additional personnel time and resources to follow-up cases and test them. To obtain the incremental cost per test, the incremental cost was divided by the total number of children and adolescents who were tested using the respective modality. The cost per diagnosis of a positive child/adolescent was calculated as the incremental cost per test divided by the number who tested positive. The relationship between uptake and unit cost was explored by plotting the incremental ILHI VT cost per test, against uptake per modality.

\section{Sensitivity analysis}

A univariate sensitivity analysis was performed on input variables for which there was a degree of uncertainty, or that constituted a significant portion of the total costs including the exchange rate and transaction costs. The impact of the RTGS conversion rate used (1USD:4 RTGS) was assessed by varying the conversion rate to the highest (1USD:1 RTGS) and lowest (1USD: 50 RTGS) observed rates during the study period. The impact of assumptions made around resource use items such as staff salaries ( $\pm 5-10 \%$,), building $( \pm 10-20 \%)$, equipment $( \pm 10-20 \%)$ and overhead costs $( \pm 10-20 \%)$ and the frequency of the refresher training $(1 /$ year $-4 /$ year) were also tested. In addition, HIV prevalence of clinic attendees was varied from 5 to $20 \%$, while yield of ILHIVT was varied from 2 to $7 \%$. Finally, transaction costs defined as management costs incurred through non-governmental organization (NGO) supervision of intervention activities (for study staff), was varied $( \pm 10$ $20 \%)$.

\section{Scenario analysis}

HIV self-testing is recommended by the WHO as an alternative HIV testing strategy for scale-up [19-21], and qualitative work conducted after the conclusion of the ILHIVT intervention indicated that lack of exposure to, 
and acceptability of caregiver-provided testing affected the uptake of this modality across all sites. We explored variations in the uptake of index-linked caregiver provided HIV testing to reflect potential real-world acceptability and implementation scenarios: 1.) equal uptake of all 3 modalities; 2.) a 50-50 split between facility based testing and testing performed by caregivers; 3 .) $100 \%$ uptake of caregiver-provided testing at all clinics. Additionally, we compared the efficiency of home-based and caregiver-provided testing (i.e. non facility-based options) by identifying the uptake of caregiver provided tests required to match the unit cost of home-based ILHIVT performed by health care workers.

\section{Results}

\section{Cost composition}

Table 2 presents recurrent and capital costs for SoC HIV testing and the three ILHIVT modalities. The total monthly cost of providing SoC testing ranged from US\$997 to US\$1410. Across these facilities, personnel costs accounted for 56.9 to $70.9 \%$ of total costs; testingspecific consumables accounted for 27.9 to $35.7 \%$; overheads from 1.2 to $9.8 \%$, and less than $1 \%$ of total costs were attributable to capital resource items. The total incremental monthly cost of providing ILHIVT ranged from $\$ 379$ to $\$ 400$ in clinic; $\$ 359$ to $\$ 420$ for homebased testing; $\$ 255$ to $\$ 288$ for caregiver-provided testing. Across all three clinics and modalities; personnel costs accounted for 39.7 to $62.4 \%$ of total costs; testingspecific consumables accounted for 4.5 to $23.1 \%$; transaction costs from 17.6 to $29.1 \%$; capital resource items for 2.6 to $6.4 \%$.

\section{HIV testing outcomes}

From May 2018 to August 2018, 2317 clinic based SoC HIV tests were administered (Table 3 ). The test yield (proportion of test results that were positive), was 12.9\% (299/2317 total tested). Across the 3 clinics 11.5\% (267/ 2317) of those tested were $2-18$ years of age, and the yield was $3.7 \%(10 / 267)$.

The 3 clinics screened 2087 index-cases, identified 1708 eligible children and adolescents of unknown HIV status, and of those, tested 1263 (74\%); 41\% in clinic, $48 \%$ via home-based testing, and 10\% through assisted testing. Uptake of each modality varied by clinic; home-based testing was the preferred option at urban clinics A (45.7\%) and B (65.9\%), while clinic testing was the preferred option at rural clinic $\mathrm{C}$ (56.2\%). The yield of ILHIVT at Clinics A, B and C was $0.6 \%(3 / 505), 0.3 \%(1 / 290)$ and $1.5 \%(7 / 468)$ respectively. Yield by modality is as follows: $1.3 \%$ (7/ 523) via clinic; $0.5 \%(3 / 611)$ via home-based; $0.8 \%$ (1/ 129) via caregiver-assisted testing (Table 3 ).

\section{Unit costs}

The cost per child/adolescent tested through SoC ranged from US $\$ 5.90$ to US $\$ 7.15$. The cost per positive SoC test result ranged from US\$35.92 to US\$61.61. The costs per HIV-positive child or adolescent, 2-18 years of age identified through SoC were US\$166.69, US\$139.76, US\$197.80 at Clinic A, B and C respectively (Table 3).

The average incremental cost per child/adolescent tested through ILHIVT at the clinic ranged from US\$10.56 (urban clinic A) to US\$25.47 (rural clinic C). The incremental cost per modality across all clinics ranged as follows: clinic - US\$5.36 (clinic C) to US $\$ 31.08$ (clinic B); home-based testing by health care worker - US\$6.69 (clinic A) to US\$8.65 (clinic C); caregiver-provided testing - US\$17.59 (clinic A) to US\$62.40 (clinic C). The cost per diagnosis of an HIV positive child/adolescent through ILHIVT ranged from US\$352.59 to US\$1492.02 for clinic based ILHIVT and US $\$ 817.21$ to US $\$ 1545.41$ via home-based testing by health care worker. Clinic $\mathrm{C}$ had the only positive test result from caregiver-provided testing, which cost US\$998.41 (Table 3). The uptake of ILHIVT via modality and associated incremental cost per test indicates that costs are likely dependent on quantity: the fewer tests administered via modality, the higher the associated incremental unit cost per test, and vice versa (Fig. 1).

\section{Sensitivity analysis}

All 4. HIV testing unit costs (SoC and ILHIVT via 3 modalities) were most sensitive to changes in the conversion rate. Figures $2 \mathrm{a}-\mathrm{d}$ present the results of the sensitivity analysis performed on the remaining variables. With regards to resource use inputs, personnel salaries had the largest influence on SoC unit costs $( \pm 3-7 \%)$, followed by overheads and the addition of up to 4 refresher trainings. Changes to capital resource inputs had a negligible effect on SoC unit costs. When considering the resource use inputs for ILHIVT across all three modalities, the unit cost per test was most sensitive to changes in clinic attendee HIV prevalence ( $\pm 9-13 \%)$, followed by personnel salaries for all 3 modalities .

The impact of changing the parameters on cost per diagnosis unit costs are presented in Supplementary Fig. 1. Cost per diagnoses were most sensitive to changes in the conversion rate. Of the resource use inputs, personnel costs had the largest influence on $\mathrm{SoC}$ unit costs, while changes to clinic attendee HIV prevalence as well as testing yield, had the largest influence on ILHI VT related unit costs.

\section{Scenario analysis}

The results of varying modality uptake and the subsequent impact on unit cost per test, compared to observed unit costs for the 4-month period in this study 


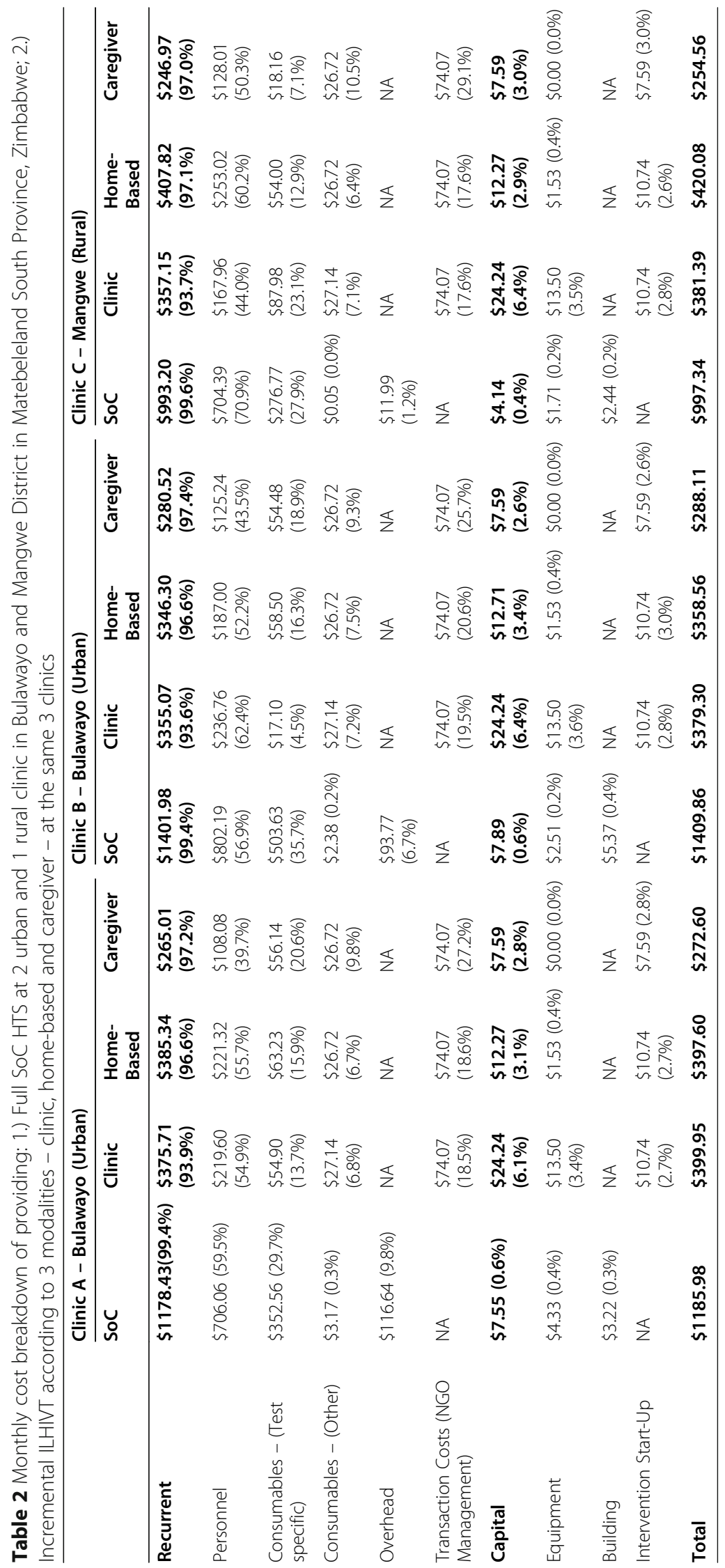


Table 3 Unit cost of the various HIV testing modalities across all three costing study clinics, over a 4 month time-period

\begin{tabular}{|c|c|c|c|c|}
\hline Testing Modality & No. Tested & No. Positive & Cost Per Test (USD) & Cost Per Diagnosis (USD) \\
\hline \multicolumn{5}{|l|}{ Clinic A - Bulawayo (Urban) } \\
\hline Standard of Care (SoC) - Total & 804 & 77 & $\$ 5.90$ & $\$ 61.61$ \\
\hline SoC 2-18 years & 113 & 4 & $\$ 5.90$ & $\$ 166.69$ \\
\hline Index-Linked-Clinic & 212 & 2 & $\$ 7.41$ & $\$ 785.50$ \\
\hline Index-Linked-Home-Based & 231 & 1 & $\$ 6.69$ & $\$ 1545.41$ \\
\hline Index-Linked-Caregiver & 62 & 0 & $\$ 17.59$ & N/A \\
\hline \multicolumn{5}{|l|}{ Clinic B - Bulawayo (Urban) } \\
\hline Standard of Care - Total & 955 & 157 & $\$ 5.91$ & $\$ 35.92$ \\
\hline SoC $2-18$ years & 71 & 3 & $\$ 5.91$ & $\$ 139.76$ \\
\hline Index-Linked-Clinic & 48 & 1 & $\$ 31.08$ & $\$ 1492.02$ \\
\hline Index-Linked-Home-Based & 191 & 0 & $\$ 7.18$ & N/A \\
\hline Index-Linked-Caregiver & 51 & 0 & $\$ 21.63$ & N/A \\
\hline \multicolumn{5}{|l|}{ Clinic C - Mangwe (Rural) } \\
\hline Standard of Care - Total & 558 & 65 & $\$ 7.15$ & $\$ 61.37$ \\
\hline SoC $2-18$ years & 83 & 3 & $\$ 7.15$ & $\$ 197.80$ \\
\hline Index-Linked-Clinic & 263 & 4 & $\$ 5.36$ & $\$ 352.59$ \\
\hline Index-Linked-Home-Based & 189 & 2 & $\$ 8.65$ & $\$ 817.21$ \\
\hline Index-Linked-Caregiver & 16 & 1 & $\$ 62.40$ & $\$ 998.41$ \\
\hline
\end{tabular}

1. Unit cost of SoC HIV testing presented for all clinics span May-Aug 2018 period

2. Incremental unit cost of index-linked testing for all modalities, presented for all clinics span Sep-Dec 2018

are presented in Table 4. If all 3 modalities have equal uptake, the unit cost of home-based testing increases and caregiver-provided testing becomes cheaper than clinic testing at urban clinics. If clinic and caregiverprovided testing have equal uptake, the unit cost of clinic testing decreases at both urban clinics but increases at the rural clinic, while unit costs of caregiverprovided testing at all three clinics decrease substantially. If all index-linked testing is via caregiver-provided testing, the cost per test at Clinic $\mathrm{A}, \mathrm{B}$ and $\mathrm{C}$ respectively, are as follows: US\$2.12, US\$6.52, US\$5.32.

In order for the caregiver - provided testing incremental unit cost per test to equate to that of ILHIVT via the home-based testing modality observed in the same 4month time period, 163, 241 and 177 caregiver-provided tests would need to be administered at clinics A, B and $\mathrm{C}$ respectively. If all participants at clinics $\mathrm{A}$ and $\mathrm{C}$ who chose home-based testing had opted for caregiver-

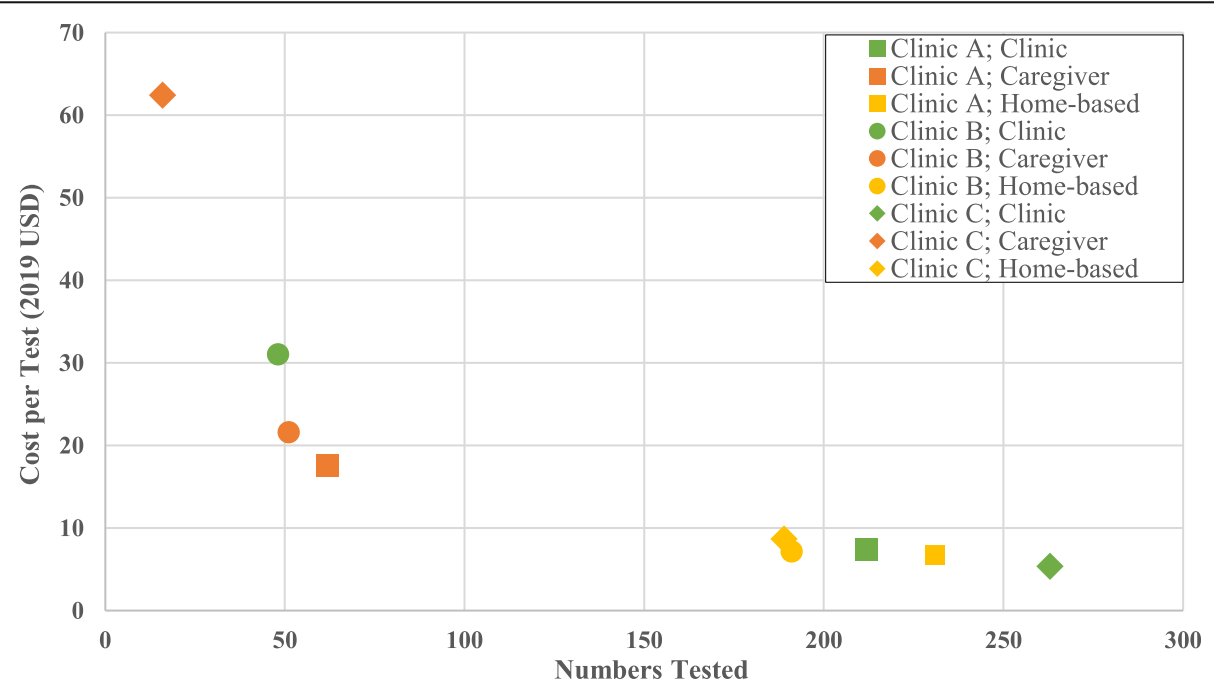

Fig. 1 Uptake of Index-Linked HIV Testing vs associated Incremental Cost per Test, according to modality: Clinic; Caregiver; Home-Based 
a

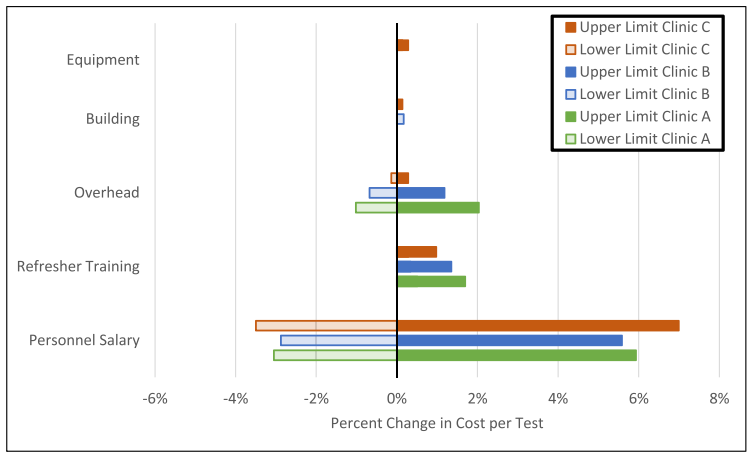

Note: Conversion rate variable was omitted due to size. Clinic A $-62 \%$ to $+201 \%$; Clinic B $-57 \%$ to $+187 \%$; Clinic C- $6 \%$ to

C

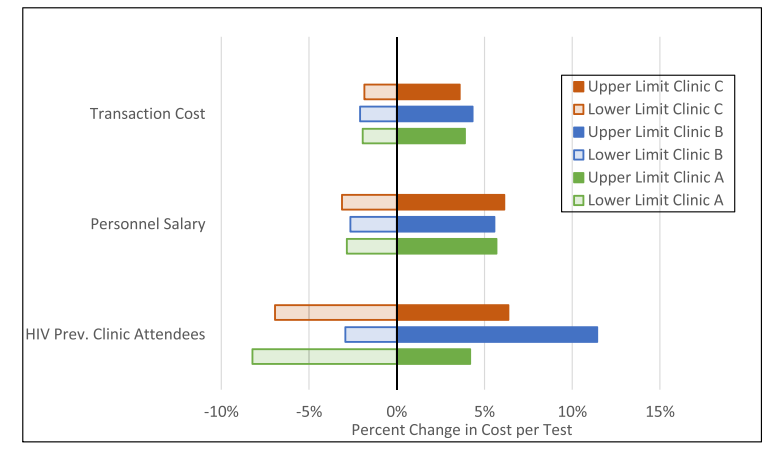

Note: conve
$+186 \%$ b

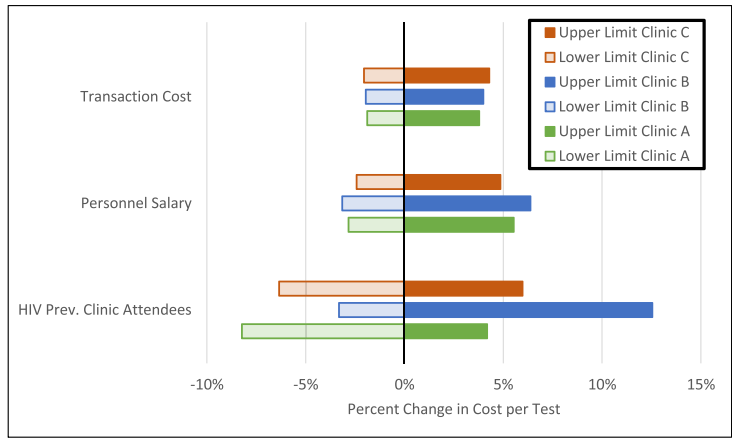

Note: conversion rate variable was omitted due to size. Clinic A $-51 \%$ to $+168 \%$; Clinic B $-58 \%$ to $+190 \%$; Clinic C - $44 \%$ to

d

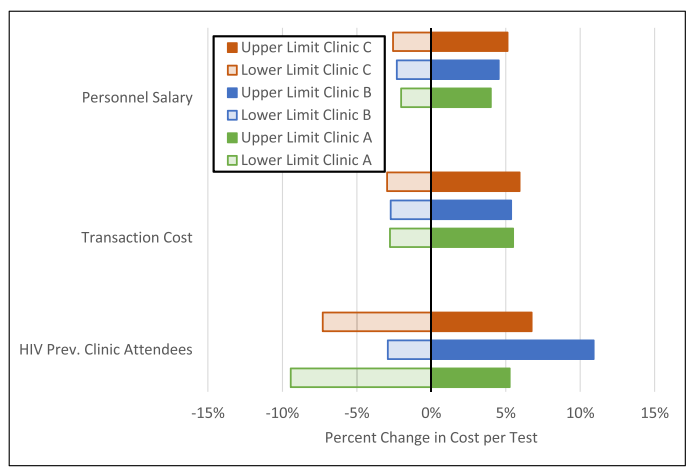

Note:

Fig. 2 a. Tornado plot of model parameters varied in univariate sensitivity analysis of Adolescent SoC HTS and impact on Cost per Test. b. Tornado plot of model parameters varied in univariate sensitivity analysis of Index-Linked Testing via Clinic modality and impact on Cost per Test. c. Tornado plot of model parameters varied in univariate sensitivity analysis of Index-Linked Testing via Home-Based modality and impact on Cost per Test. d. Tornado plot of model parameters varied in univariate sensitivity analysis of Index-Linked Testing via Caregiver modality and impact on Cost per Test

Table 4 Scenario analysis of varying index-linked modality preference/uptake across all clinics: change in Unit Cost - Cost per Test

\begin{tabular}{clll}
\hline & Clinic & Home-Based & Caregiver \\
\hline Clinic A - Original Unit Cost & $\mathbf{7 . 4 1}$ & $\mathbf{6 . 6 9}$ & $\mathbf{1 7 . 7 9}$ \\
Equal - 1/3 Distribution & $\$ 9.10$ & $\$ 8.85$ & $\$ 6.36$ \\
50:50 -Clinic/Caregiver & $\$ 6.37$ & $\mathrm{~N} / \mathrm{A}$ & $\$ 4.24$ \\
Caregiver Only & $\mathrm{N} / \mathrm{A}$ & $\mathrm{N} / \mathrm{A}$ & $\$ 2.12$ \\
Clinic B - Original Unit Cost & $\mathbf{3 1 . 0 8}$ & $\mathbf{7 . 1 8}$ & $\mathbf{2 1 . 6 3}$ \\
Equal -1/3 Distribution & $\$ 15.89$ & $\$ 13.32$ & $\$ 12.97$ \\
50:50 -Clinic/Caregiver & $\$ 10.89$ & $\mathrm{~N} / \mathrm{A}$ & $\$ 9.75$ \\
Caregiver Only & $\mathrm{N} / \mathrm{A}$ & $\mathrm{N} / \mathrm{A}$ & $\$ 6.52$ \\
Clinic C - Original Unit Cost & $\mathbf{5 . 3 6}$ & $\mathbf{8 . 6 5}$ & $\mathbf{6 2 . 4 0}$ \\
Equal -1/3 Distribution & $\$ 8.42$ & $\$ 10.29$ & $\$ 9.36$ \\
50:50 -Clinic/Caregiver & $\$ 5.92$ & $\mathrm{~N} / \mathrm{A}$ & $\$ 7.34$ \\
Caregiver Only & $\mathrm{N} / \mathrm{A}$ & $\mathrm{N} / \mathrm{A}$ & $\$ 5.32$ \\
\hline
\end{tabular}

provided testing instead, it might have been possible to observe the lower situational caregiver - provided testing unit cost per test.

\section{Discussion}

Our findings show that 6 times more children/adolescents were tested via ILHIVT compared to SoC HIV testing over the observed period. HIV prevalence among children/adolescents accessing SoC HIV testing (4\%), was much higher than children/adolescents $(0.7 \%)$ tested via ILHIVT. The cost of SoC HIV testing was lower in urban than rural settings, due to a greater number of tests administered at the urban clinics (44-71\% more) and larger catchment populations. The cost of ILHIVT modalities were dependent on, and varied according to uptake. Costs involved in delivering SoC HTS were primarily driven by personnel followed by consumables. Whereas personnel followed by transaction costs were the largest drivers of ILHIVT costs at both urban and rural clinics. While management costs will be an important component of ensuring quality as well as accountability in strategies such as 
this that rely on identifying potential cases and outreach to the community, the management of this type of service delivery may need to be streamlined in an effort to keep transaction costs low.

The cost of delivering HIV testing through standard clinic-based services in this study ranged from US $\$ 5.90$ to US\$7.15, and is comparable to recent STAR project estimates from Malawi, Zambia and Zimbabwe (2016 US\$4.24 to US\$7.65) [22], yet higher compared to the results of a systematic review evaluating the cost of HTC in South Africa (2017/2018 US\$3.62) [23]. The cost per positive diagnosis through standard clinic services in this study was lower than STAR estimates (US\$73.63 to US\$178.92) and likely reflects the higher HIV prevalence of those accessing testing among our study population (13\%), compared to the STAR project (7\%) [22].

In contrast, the high cost per diagnosis associated with ILHIVT was due to a low prevalence of HIV among index-linked children. An estimated $>90 \%$ of children living with HIV are vertically infected; those who were born prior to the scale up of prevention of mother to child transmission (PMTCT) programs are now likely to be adolescents and would therefore be diagnosed only when symptomatic, resulting in worse outcomes than those diagnosed and initiated on treatment in infancy [13, 24]. SoC HIV testing is likely to diagnose children with advanced disease, whereas asymptomatic children may not be brought to the clinic. Other studies of the same agegroup in Zimbabwe found higher prevalence (2.6-15\%) $[11,25]$, and index-linked testing of sexual partners and biological children in 3 rural provinces found a 30\% HIV prevalence [12]. A study in Cameroon where only $46.2 \%$ of indexes consented to have their children tested, diagnosed HIV infection in $6.8 \%$ of children tested [24], while another index-linked study in Lesotho found an HIV prevalence of $1.8 \%$ among biological children of indexes [26]. The low HIV prevalence among index cases at the BGAP clinics is likely attributable to recent HIV testing campaigns potentially resulting in saturation of testing, including a large Population Services International testing campaign operating in the area and exclusion of children/ adolescents tested $>6$ months prior to B-Gap screening.

HIV case finding will become more costly as knowledge of HIV status and treatment coverage increase. Alternative community based HIV testing strategies such as homebased testing and HIV Self-Test have been evaluated using costing studies $[19,27,28]$, but this is the first costing study to evaluate index-linked testing, a strategy proposed by the WHO in order to expand HTC [29]. Our results provide the first unit costs of the different ILHVIT modalities for sub-Saharan Africa but they do not provide information on the cost-effectiveness of the strategy. While a full economic evaluation is necessary to accurately estimate the costeffectiveness of ILHIVT, Phillips et al. (2019) have shown that cost per diagnosis can be used as a proxy for costeffectiveness of HIV testing programs, and estimated a value for the cost-effectiveness threshold (2018) US $\$ 315$ per HIV diagnosis [30]. By this definition, none of the index-linked modalities in our analysis would be considered cost-effective as the lowest cost per diagnosis estimated was US\$385.35. However, our sensitivity analysis illustrated that when ILHI VT yield was increased from 0.7 to $7 \%$, (as observed in Cameroon [24]), all but two modalities (clinic testing at an urban clinic, and rural caregiver-provided testing), resulted in cost per diagnoses below that US $\$ 315$ threshold. ILHIVT cost per diagnosis would be more cost-effective if targeted to a higher-prevalence population. For example, a more efficient solution for scaling up ILHIVT could be to test the entire household; costs would be shared across a greater number of tests and yield would likely increase as adults have a higher prevalence of HIV compared to children/adolescents - although measures would need to be in place to ensure services screen out those previously diagnosed and on ART [27], and those testing are effectively linked to HIV treatment or prevention. A scale-up of any version of ILHI VT - in its current format, or expanded to the entire household - to either the regional or national level, requires careful consideration of the implications of potential (dis) economies of scale as well as other cost drivers. While this study explored drivers of cost at the facility level, and expected uptake is critical to this setting, physical capacity and infrastructure investment costs necessitate scrutiny at the regional or national level [31]. Furthermore, costs involved in geographical variability with regards to transport, training, management, monitoring and evaluation, quality assurance, as well as socio-cultural variability and acceptability affecting demand, must be considered [32].

HIV self-testing has the advantages of convenience, discretion and confidentiality, compared to clinic based HTS [33, 34]. HIV self-test has shown high acceptability and uptake elsewhere which resulted in WHO guidelines recommending scale-up [19-21]. In this study 'self-test' however referred to caregiver assisted testing of a child/ adolescent. Caregiver uncertainty about correctly administering the test to a child without the aid of a health care professional, as well as fear of how to counsel a child with a positive result, could be factors accounting for the low levels of uptake within this study [35]. SoC clinic based HIV testing, when supplemented with HIV self-testing, can be a cost-effective testing option in a population with a high HIV prevalence and has the capacity to extend coverage rates, and therefore diagnoses [28, 33]. In this study, because assisted-testing had very low uptake, the incremental unit costs were 3.0 times greater than the cheapest modality (home-based) in an urban setting, and 11.6 times higher than the cheapest modality (clinic) in a rural setting. This low uptake raises questions around the differences of administering a self-test to someone else, 
compared to self-administration. Exploration into the dynamics and differences between HIV self-test and assisted self-test are needed.

To our knowledge, this study is the first to estimate the cost of ILHIVT in any setting. A limitation is that only 3 clinics were included. Although both urban and rural clinics are represented, showing that the cost and efficiency of each modality varies according to setting, it should be noted that the urban and rural clinics were located in different districts. While Bulawayo is an entirely urban district, and Mangwe an entirely rural district, there may be unique structural and/or district level factors which also influence unit costs. Additionally, the study was conducted within an economically unstable context. Zimbabwe dollarized its economy in 2008 following hyperinflation. In 2018 it introduced its own currency (RTGS), which triggered rapid inflation. In this study all RTGS amounts were converted to USD at the prevailing rate. Costs were highly sensitive to conversion rate as a result of the rapid inflation of RTGS against the US dollar.

\section{Conclusion}

Innovative and alternative HIV testing strategies above $\mathrm{SoC}$ approaches are necessary in order to reach children and adolescents, given the additional barriers they face in order to get tested. The results of our study confirm that both costs and uptake of ILHIVT vary with setting. In addition, while ILHIVT allows for greater access of this difficult to reach population, compared to the standard method, uptake is a key driver of the cost per test. To ensure efficiency when scaling up ILHIVT, acceptability of testing modality needs to be considered and alternative index linked testing solutions that increase yield such as ILHIVT of the entire household, as opposed to solely targeting children/adolescents, need to be explored. Additionally, there is potential to benefit from economies of scope by integrating ILHIVT with other activities, however this would require further consideration and research.

\section{Appendix 1}

Summary of time tracking diaries for ILHIVT activities: compiled via direct observation and self-evaluation Time tracking diaries completed by the costing team through direct observation, as well as time tracking diaries completed by research assistants through selfevaluation had the same format: an activity code, a description of the activities and a table which divided the workday into half hour increments. The following illustrates an abbreviated version of how human resource use was delineated and recorded.

Instructions: Using the activity codes below, please record the appropriate activity for each half hour interval of your work day, over the course of one consecutive week. If activities conducted do not fall into one of the pre-listed activities below, please specify the activity in the blank codes (code 13-15), and enter into the table.

\begin{tabular}{|c|c|}
\hline $\begin{array}{l}\text { Activity } \\
\text { Code }\end{array}$ & Description of Activity \\
\hline 01 & $\begin{array}{l}\text { Organization/Administrative Activities (Ex. Preparing } \\
\text { CRFs for use the next day, photo copying, filing, filling out } \\
\text { petty cash ledger etc.) }\end{array}$ \\
\hline 02 & $\begin{array}{l}\text { Screening Index Cases, Including morning health talk and } \\
\text { evaluating self-testing competency }\end{array}$ \\
\hline 03 & Testing Children/Adolescents of Index Cases \\
\hline 04 & $\begin{array}{l}\text { Filling out CRFs (All CRFs: Enrolment, Outcome, Locator, } \\
\text { etc.) }\end{array}$ \\
\hline 05 & $\begin{array}{l}\text { Follow-Up, including phone calls made for testing } \\
\text { reminders, initiating testing \& following-up of results with } \\
\text { community partners, linking to treatment, enrolling in } \\
\text { CHW intervention, etc. }\end{array}$ \\
\hline 06 & $\begin{array}{l}\text { Outcome Assessment, including exit interview, sample } \\
\text { collection, sending sample out for processing }\end{array}$ \\
\hline 07 & $\begin{array}{l}\text { Meetings (Ex. With study coordinator; at clinic; with } \\
\text { community partners; with stakeholders) }\end{array}$ \\
\hline 08 & $\begin{array}{l}\text { Assisting clinic staff with non-B-Gap related tasks (Ex. } \\
\text { Testing O/I patients) }\end{array}$ \\
\hline 09 & $\begin{array}{l}\text { Breaks and Down-Time (Ex. During a slow day, waiting for } \\
\text { patients etc.) }\end{array}$ \\
\hline 10 & Community Testing (Home Visits) \\
\hline 11 & Travelling to households for community testing \\
\hline 12 & Collection of Assisted Self-Test kits \\
\hline 13 & \\
\hline
\end{tabular}

Time of Day Monday Tuesday Wednesday Thursday Friday 08:00-08:30

08:30-09:00

Etc.

A total of 56 direct observation hours and 535 selfevaluation hours were recorded via the time tracking diaries. Daily activity breakdown is classified into three categories and presented below: Clinic Hours; Community Hours; Administration

\begin{tabular}{llll}
\hline \multicolumn{4}{l}{ Allocation of Human Resource Use Involved in ILHIVT Activities: } \\
\multicolumn{3}{l}{ Percent of Time Spent } \\
\hline Clinic & $\begin{array}{l}\text { Clinic } \\
\text { Hours }\end{array}$ & $\begin{array}{l}\text { Community } \\
\text { Hours }\end{array}$ & Administration \\
\hline $\begin{array}{l}\text { A - Bulawayo } \\
\text { (Urban) }\end{array}$ & $20.3 \%$ & $20.6 \%$ & $59.1 \%$ \\
$\begin{array}{l}\text { B - Bulawayo } \\
\text { (Urban) }\end{array}$ & $22.1 \%$ & $11.3 \%$ & $66.7 \%$ \\
C- Mangwe (Rural) & $7.3 \%$ & $22.8 \%$ & $70.0 \%$ \\
\hline
\end{tabular}




\section{Appendix 2}

Table 5 Detailed Description of Cost Resource Collection: Methods

\begin{tabular}{|c|c|c|}
\hline Cost Category & Primary Method of Data Collection & Details \\
\hline \multicolumn{3}{|l|}{ Recurrent Costs } \\
\hline Personnel & $\begin{array}{l}\text { HTS: Interviewing the Nurse-In-Charge } \\
\text { Index-Linked-Testing: } \\
\text { Interviews with the study coordinator and } \\
\text { research assistants, in addition to direct } \\
\text { observation }\end{array}$ & $\begin{array}{l}\text { HTS: } \\
\text { - When all clinic staff was recorded, clinic staff time was measured through } \\
\text { direct observation, with a particular focus on the HTS. } \\
\text { - A PCC at each clinic was observed for a full work day, by two separate } \\
\text { individuals, and was also interviewed. } \\
\text { Index-Linked-Testing: } \\
\text { - Study personnel demarcate their time solely to index-linked testing activities. } \\
\text { As a result time-tracking diaries were completed by study personnel to detail } \\
\text { time spent on specific activities over the course of the study, and directly ob- } \\
\text { served while in clinic also. } \\
\text { - } 6 \text { research assistants completed diaries spanning } 2 \text { weeks each. } \\
\text { - Direct observation was completed by } 2 \text { separate individuals, observing each } \\
\text { of the } 6 \text { assistants for } 1 \text { day each. }\end{array}$ \\
\hline Consumables & $\begin{array}{l}\text { HTS: Interviewing the primary care counsellors } \\
\text { Index-Linked-Testing: } \\
\text { Interviewing study research assistants }\end{array}$ & $\begin{array}{l}\text { HTS: First, PCCs were asked to specify every consumable which was required } \\
\text { for an HTS client. Then each item was catalogued by natural unit - ex. } 500 \mathrm{~g} \\
\text { bag of absorbent cotton, } 1 \text { roll per bag. Following this, each consumable was } \\
\text { quantified per consumption length - ex. one pack of cotton lasts on average, } \\
3.5 \text { weeks. Use was then calculated monthly (ex. } 1.14 \text { pack/month), and } \\
\text { monthly use was then extrapolated to cover a one-year time period. } \\
\text { Index-Linked-Testing: Method, same as above. }\end{array}$ \\
\hline Training & $\begin{array}{l}\text { HTS: Interviewing the Nurse-in-Charge/District } \\
\text { Medical Officer } \\
\text { Index-Linked-Testing: Abstracting study } \\
\text { accounting files and interview with study } \\
\text { coordinator. }\end{array}$ & Frequency of training and refresher training sessions was noted. \\
\hline $\begin{array}{l}\text { Transportation/ } \\
\text { Duties }\end{array}$ & $\begin{array}{l}\text { Index-Linked-Testing (only): } \\
\text { Abstracting study accounting files }\end{array}$ & $\begin{array}{l}\text { Frequency and amount of duties related to index-linked testing consumables } \\
\text { was noted. }\end{array}$ \\
\hline Overheads & $\begin{array}{l}\text { HTS: Interviewing nurse-in-charge } \\
\text { Index-Linked-Testing: Abstracting study } \\
\text { accounting files }\end{array}$ & $\begin{array}{l}\text { HTS: Overheads were collected and then apportioned according to HTS usage, } \\
\text { compared to the size of the other clinic departments. } \\
\text { Index-Linked-Testing: Abstracting study accounting files. }\end{array}$ \\
\hline Lab-Processing & $\begin{array}{l}\text { Index-Linked-Testing (only): } \\
\text { Abstracting study accounting files }\end{array}$ & $\begin{array}{l}\text { Frequency and amount of processing fees related to viral load suppression } \\
\text { assessment was noted. }\end{array}$ \\
\hline \multicolumn{3}{|l|}{ Capital Costs } \\
\hline $\begin{array}{l}\text { Building/ } \\
\text { Facility Space }\end{array}$ & $\begin{array}{l}\text { HTS: Direct observation and physically pacing/ } \\
\text { spacing the clinic. }\end{array}$ & The area of the clinic and HTS were manually measured. \\
\hline $\begin{array}{l}\text { Furniture and } \\
\text { Equipment }\end{array}$ & $\begin{array}{l}\text { HTS: Direct observation and recording } \\
\text { Index-Linked-Testing: Direct observation, } \\
\text { recording and abstracting study accounting files }\end{array}$ & $\begin{array}{l}\text { Furniture and equipment directly involved in service provision were physically } \\
\text { counted and recorded. }\end{array}$ \\
\hline $\begin{array}{l}\text { Intervention } \\
\text { Start - Up }\end{array}$ & $\begin{array}{l}\text { Index-Linked-Testing (only): } \\
\text { Abstracting study accounting files }\end{array}$ & $\begin{array}{l}\text { Frequency and financial resources invested in initial RA training, as well as RA } \\
\text { rapid diagnostic and OMT testing training, was noted. }\end{array}$ \\
\hline
\end{tabular}




\section{Appendix 3}

Table 6 Detailed Description of Cost Resource Collection: Interviews

Interviewee Purpose

HTS

1 Nurse in Charge at each of the 3 clinics (supplemented by at least one other RGN at each clinic)

1 Primary Care Counsellor at each of the three clinics

Assistant Director of Bulawayo City Council (BCC) and BCC finance department

Provincial Medical Director and MAT South finance department

District Medical Director (Mangwe)

District Environmental Health Officer (Mangwe)

MAT South Pharmacist

Index-Linked Testing

Research Coordinator

6 Research Assistants; 2 at each of the three clinics

BRTI Study Accountant
To obtain:

- Rundown of all clinic personnel and their roles

- All inputs included in clinic overheads

To obtain:

- Activity breakdown of HTS

- Resource data collection involved in HTS

To obtain:

- Bulawayo clinic personnel salary schedule

- Costs per training/refresher training workshops related to HTS

- All overhead costs

To obtain Mangwe clinic personnel salary schedule

To obtain:

- Salary for district's HIV focal person

- Costs per training/refresher training workshops related to HTS

To obtain Mangwe clinic overhead costs

To obtain HTS consumable costs

To understand overall flow of study, obtain outcome data, query clarifications

To discern daily activity breakdown and recurrent resources consumed over the course of study activities

To obtain all study related costs:

- RA salary schedule

- Study consumable costs

- Recurrent costs: Overheads and Training

To obtain equipment costs 


\section{Abbreviations}

HIV: Human Immunodeficiency Virus; ART: Antiretroviral Therapy; ILHI VT: Index-Linked HIV Testing; WHO: World Health Organization; BGAP: Bridging the GAP in HIV Testing and Care for Children in Zimbabwe; SoC: Standard of Care; HTC: HIV Testing and Counselling; OMT: Oral Mucosal Transudate; RTGS: Real-Time Gross Settlement; USD: United States Dollars; GDP: Gross Domestic Product; NGO: Non-Governmental Organization

\section{Supplementary Information}

The online version contains supplementary material available at https://doi. org/10.1186/s12913-021-07070-3.

Additional file 1: Supplementary Figure 1. Sensitivity Analysis:

Tornado Plots Illustrating Parameter Impact on Cost per Diagnosis.

\section{Acknowledgements}

We would like to thank the Ministry of Health and Child Care Zimbabwe, Bulawayo and Mangwe clinic staff, study participants, RAs, Ivan Chigonde at Biomedical Research and Training Institute, as well as everyone at Bulawayo City Council and Matebeleland South Province offices, involved in procuring the pricing lists.

\section{Authors' contributions}

AV, LG, HM and VS conceptualized the study, developed methods and data collection tools, and analyzed data. CDC was parent study coordinator. AV, CDC, TC, RC and KN made substantial contributions to acquisition of data. GN contributed to the conception and design of the parent study. RAF conceptualized the overall project. All authors have read and approved the final draft and declare no competing interests.

\section{Funding}

This study is jointly funded by the UK Medical Research Council (MRC) and the UK Department for International Development (DFID) under the MRC/ DFID Concordat agreement [MR/P011268/1]. The funding body had no role in the design of this study, the collection, analysis and interpretation of data, nor in writing the manuscript.

\section{Availability of data and materials}

The datasets during and/or analyzed during the current study available from the corresponding author on reasonable request.

\section{Declarations}

\section{Ethics approval and consent to participate}

Approval for the B-GAP study was obtained from the London School of Hygiene \& Tropical Medicine research ethics committee (ref 12263-2), the Medical Research Council of Zimbabwe (ref MRCZ/A/2167) and the institutional review board of the Biomedical Research and Training Institute (ref. AP138/ 2017). Individual patient level data was not presented in this manuscript; written consent to participate was obtained for the parent study.

\section{Consent for publication}

Not applicable.

\section{Competing interests}

The authors have no financial or other competing interests to declare.

\section{Author details}

'Department of Infectious Disease Epidemiology, London School of Hygiene and Tropical Medicine, London, UK. ${ }^{2}$ Institute for Global Health Innovation, Imperial College London, London, UK. ${ }^{3}$ MRC International Statistics and Epidemiology Group, London School of Hygiene and Tropical Medicine, London, UK. ${ }^{4}$ Biomedical Research and Training Institute, Harare, Zimbabwe. ${ }^{5}$ Department of Clinical Research, London School of Hygiene and Tropical Medicine, London, UK. ${ }^{6}$ Health Economics Unit, University of Cape Town, Cape Town, South Africa. ${ }^{7}$ Matebeleland South, Ministry of Health and Child Care, Bulawayo, Zimbabwe. ${ }^{8}$ City Health Department, Bulawayo City Council, Bulawayo, Zimbabwe. ${ }^{9}$ Ministry of Health and Child Care, Harare, Zimbabwe.

${ }^{10}$ London School of Hygiene and Tropical Medicine, London, UK.
Received: 24 January 2021 Accepted: 22 September 2021

Published online: 12 October 2021

\section{References}

1. UNAIDS. Ending AIDS: Progress Towards the 90-90-90 Targets. 2017.

2. UNAIDS. Miles To Go - Globals AIDS Update 2018. 2018.

3. UNAIDS. Progress towards the Start Free, Stay Free, AIDS Free targets; 2020 Report. 2020.

4. UNAIDS. Global HIV \& AIDS statistics - 2020 fact sheet. 2020.

5. Lowenthal ED, Bakeera-Kitaka S, Marukutira T, Chapman J, Goldrath K, Ferrand RA. Perinatally acquired HIV infection in adolescents from subSaharan Africa: a review of emerging challenges. Lancet Infect Dis. 2014; 14(7):627-39. https://doi.org/10.1016/S1473-3099(13)70363-3.

6. St Clair-Sullivan N, Mwamba C, Whetham J, Bolton Moore C, Darking M, Vera J. Barriers to HIV care and adherence for young people living with HIV in Zambia and mHealth. Mhealth. 2019;5:45. https://doi.org/10.21037/mhea Ith.2019.09.02.

7. Slogrove AL, Sohn AH. The global epidemiology of adolescents living with HIV: time for more granular data to improve adolescent health outcomes. Curr Opin HIV AIDS. 2018;13(3):170-8. https://doi.org/10.1097/COH. 0000000000000449.

8. UNAIDS. All In: End Adolescent AIDS; 2015.

9. Ahmed S, Sabelli RA, Simon K, Rosenberg NE, Kavuta E, Harawa M, et al. Index case finding facilitates identification and linkage to care of children and young persons living with HIV/AIDS in Malawi. Tropical Med Int Health. 2017:22(8):1021-9. https://doi.org/10.1111/tmi.12900.

10. Cohen $D$, Lungu $M$, van Oosterhout JJ. HIV testing coverage of family members of adult antiretroviral therapy patients in Malawi. AIDS Care. 2010; 22(11):1346-9. https://doi.org/10.1080/09540121003720986.

11. Ferrand RA, Munaiwa L, Matsekete J, Bandason T, Nathoo K, Ndhlovu CE, et al. Undiagnosed HIV infection among adolescents seeking primary health care in Zimbabwe. Clin Infect Dis. 2010;51(7):844-51. https://doi.org/10.1 086/656361.

12. Mahachi N, Muchedzi A, Tafuma TA, Mawora P, Kariuki L, Semo BW, et al. Sustained high HIV case-finding through index testing and partner notification services: experiences from three provinces in Zimbabwe. J Int AIDS Soc. 2019;22 Suppl 3:e25321.

13. Wagner AD, Mugo C, Njuguna IN, Maleche-Obimbo E, Sherr K, Inwani IW, et al. Implementation and operational research: active referral of children of HIV-positive adults reveals high prevalence of undiagnosed HIV. J Acquir Immune Defic Syndr. 2016;73(5):e83-e9. https://doi.org/10.1097/QAl. 0000000000001184

14. Dziva Chikwari C, Simms V, Dringus S, Kranzer K, Bandason T, Vasantharoopan A, et al. Evaluating the effectiveness and cost-effectiveness of health facility-based and community-based index-linked HIV testing strategies for children: protocol for the B-GAP study in Zimbabwe. BMJ Open. 2019;9(7):e029428. https://doi.org/10.1136/bmjopen-2019-029428.

15. Global Health Cost Consortium. Reference case for Global Health costing. 2017

16. WHO. Cost effectiveness and strategic planning (WHO-CHOICE); Prices used for tradable goods in WHO-CHOICE. 2020.

17. Reserve Bank Of Zimbabwe. Exchange Rates. 2019.

18. World Bank. Inflation, GDP deflator (annual \%). 2018

19. Maheswaran H, Petrou S, MacPherson P, Choko AT, Kumwenda F, Lalloo DG, et al. Cost and quality of life analysis of HIV self-testing and facility-based HIV testing and counselling in Blantyre. Malawi BMC Med. 2016:14(1):34. https://doi.org/10.1186/s12916-016-0577-7.

20. Indravudh PP, Fielding K, Kumwenda MK, Nzawa R, Chilongosi R, Desmond $\mathrm{N}$, et al. Community-led delivery of HIV self-testing to improve HIV testing, ART initiation and broader social outcomes in rural Malawi: study protocol for a cluster-randomised trial. BMC Infect Dis. 2019;19(1):814. https://doi. org/10.1186/s12879-019-4430-4

21. Indravudh PP, Choko AT, Corbett EL. Scaling up HIV self-testing in subSaharan Africa: a review of technology, policy and evidence. Curr Opin Infect Dis. 2018;31(1):14-24. https://doi.org/10.1097/QCO.0000000000000426.

22. Mwenge L, Sande L, Mangenah C, Ahmed N, Kanema S, d'Elbee M, et al. Costs of facility-based HIV testing in Malawi, Zambia and Zimbabwe. PLoS One. 2017;12(10):e0185740. https://doi.org/10.1371/journal.pone.0185740.

23. Meyer-Rath G, van Rensburg C, Chiu C, Leuner R, Jamieson L, Cohen S. The per-patient costs of HIV services in South Africa: systematic review and 
application in the south African HIV investment case. PLoS One. 2019;14(2): e0210497. https://doi.org/10.1371/journal.pone.0210497.

24. Yumo HA, Ajeh RA, Sieleunou I, Ndenkeh JN Jr, Jordan MR, Sam-Agudu NA, et al. Parental and child-level predictors of HIV testing uptake, seropositivity and treatment initiation among children and adolescents in Cameroon. PLoS One. 2020;15(4):e0230988. https://doi.org/10.1371/journal.pone.023 0988.

25. Simms V, Dauya E, Dakshina S, Bandason T, McHugh G, Munyati S, et al. Community burden of undiagnosed HIV infection among adolescents in Zimbabwe following primary healthcare-based provider-initiated HIV testing and counselling: a cross-sectional survey. PLoS Med. 2017;14(7):e1002360. https://doi.org/10.1371/journal.pmed.1002360.

26. Jubilee M, Park FJ, Chipango K, Pule K, Machinda A, Taruberekera N. HIV index testing to improve HIV positivity rate and linkage to care and treatment of sexual partners, adolescents and children of PLHIV in Lesotho. PLoS One. 2019;14(3):e0212762. https://doi.org/10.1371/journal.pone.0212 762.

27. Lasry A, Bachanas P, Suraratdecha C, Alwano MG, Behel S, Pals S, et al. Cost of community-based HIV testing activities to reach saturation in Botswana. AIDS Behav. 2019;23(4):875-82. https://doi.org/10.1007/s10461-019-02408-9.

28. Maheswaran $\mathrm{H}$, Clarke A, MacPherson P, Kumwenda F, Lalloo DG, Corbett

EL, et al. Cost-effectiveness of community-based human immunodeficiency virus self-testing in Blantyre. Malawi Clin Infect Dis. 2018;66(8):1211-21. https://doi.org/10.1093/cid/cix983.

29. WHO. Service Delivery Approaches to HIV Testing and Counselling (HTC): A Strategic HTC Programme Framework. 2012

30. Phillips AN, Cambiano V, Nakagawa F, Bansi-Matharu L, Wilson D, Jani I, et al. Cost-per-diagnosis as a metric for monitoring cost-effectiveness of HIV testing programmes in low-income settings in southern Africa: health economic and modelling analysis. J Int AIDS Soc. 2019;22(7):e25325. https:// doi.org/10.1002/jia2.25325

31. Kumaranayake $L$. The economics of scaling up: cost estimation for HIV/AIDS interventions. AIDS. 2008;22(Suppl 1):S23-33. https://doi.org/10.1097/01.aids. $0000327620.47103 .1 \mathrm{~d}$.

32. Johns B, Torres $T$, Who C. Costs of scaling up health interventions: a systematic review. Health Policy Plan. 2005;20(1):1-13. https://doi.org/10.1 093/heapol/czi001.

33. Johnson LF, van Rensburg C, Govathson C, Meyer-Rath G. Optimal HIV testing strategies for South Africa: a model-based evaluation of populationlevel impact and cost-effectiveness. Sci Rep. 2019;9(1):12621. https://doi. org/10.1038/s41598-019-49109-w.

34. Cambiano V, Ford D, Mabugu T, Napierala Mavedzenge S, Miners A, Mugurungi $\mathrm{O}$, et al. Assessment of the potential impact and costeffectiveness of self-testing for HIV in low-income countries. J Infect Dis. 2015;212(4):570-7. https://doi.org/10.1093/infdis/jiv040.

35. Rainer C, Chihota B, Dziva Chikwari C, McHugh G, Dauya E, Mujuru H, et al. Adolescents' and caregivers' perceptions of caregiver-provided testing and HIV self-testing using oral mucosal transudate tests in Zimbabwe: a short report. AIDS Care. 2020;33(1):1-5. https://doi.org/10.1080/09540121.2020.174 9226

\section{Publisher's Note}

Springer Nature remains neutral with regard to jurisdictional claims in published maps and institutional affiliations.

\section{Ready to submit your research? Choose BMC and benefit from:}

- fast, convenient online submission

- thorough peer review by experienced researchers in your field

- rapid publication on acceptance

- support for research data, including large and complex data types

- gold Open Access which fosters wider collaboration and increased citations

- maximum visibility for your research: over $100 \mathrm{M}$ website views per year

At BMC, research is always in progress.

Learn more biomedcentral.com/submissions 